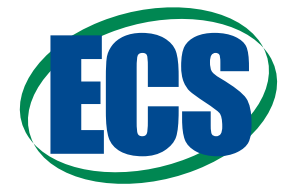

\title{
Optimal Utilization of Combined Double Layer and Nernstian Charging of Activated Carbon Electrodes in Aqueous Halide Supercapattery through Capacitance Unequalization
}

\author{
Bamidele Akinwolemiwa, ${ }^{1}$ Chaohui Wei, ${ }^{1}$ Qinghua Yang, ${ }^{2}$ Linpo Yu, ${ }^{2}$ Lan Xia, ${ }^{2}$ Di Hu, \\ Chuang Peng, $\mathbb{1}^{2,3, \mathrm{z}}$ and George $Z$. Chen $\mathbb{C}^{2,4, \mathrm{z}}$ \\ ${ }^{I}$ International Doctoral Innovation Centre, Faculty of Science and Engineering, The University of Nottingham Ningbo \\ China, Ningbo 315100, People's Republic of China \\ ${ }^{2}$ Department of Chemical and Environmental Engineering, Faculty of Science and Engineering, The University of \\ Nottingham Ningbo China, Ningbo 315100, People's Republic of China \\ ${ }^{3}$ School of Resource and Environmental Sciences, Hubei Scientific and Technological Cooperation Base of Resource \\ and Energy, Wuhan University, Wuhan 430072, People's Republic of China \\ ${ }^{4}$ Department of Chemical and Environmental Engineering, and Advanced Materials Research Division, Faculty of \\ Engineering, The University of Nottingham, Nottingham NG7 2RD, United Kingdom
}

\begin{abstract}
Charge storage through electric double layer (EDL) charging of activated carbon (AC) and redox reactions of iodide and bromide ions in aqueous electrolytes and at the $\mathrm{AC} \mid$ electrolyte interface has been investigated by cyclic voltammetry and galvanostatic charging and discharging. Electrochemical experiments were carried out in both the three-electrode and two-electrode cells with the latter resembling the so-called supercapacitor-battery hybrid or simply supercapattery. By comparing the electrochemical behavior of bromide and iodide ions used as dissolved redox species (DRS), some observed features of the supercapattery are described and analyzed from the standpoint of the EDL charging of the AC electrodes, the thermodynamics and kinetics of the electrode reactions of the DRS, and the adsorption and transport of the charging reaction products. Furthermore, the effect of capacitance unequalization was explored for the adequate utilization of the charge storage from both the DRS and EDL contributions. It is also shown that counter-electrode oversizing has to be critically appraised for the design of optimal devices.

(c) The Author(s) 2018. Published by ECS. This is an open access article distributed under the terms of the Creative Commons Attribution 4.0 License (CC BY, http://creativecommons.org/licenses/by/4.0/), which permits unrestricted reuse of the work in any medium, provided the original work is properly cited. [DOI: 10.1149/2.0031902jes]

(cc) BY
\end{abstract}

Manuscript submitted November 6, 2018; revised manuscript received December 19, 2018. Published December 29, 2018.

Charge storage in electrochemical energy storage (EES) devices can be achieved through one or combination of two or three mechanisms, namely the non-faradaic capacitive (NFC), capacitive faradaic $(\mathrm{CF})$, and non-capacitive faradaic (NCF) processes. ${ }^{1}$ The NFC mechanism refers specifically to the electric double layer (EDL) capacitance, involving polarization of the electrode / electrolyte $(\mathrm{E} \mid \mathrm{E})$ interface without any electron transfer reaction. For example, when ions with an opposite charge to the net-surface charge on a porous carbon electrode (with negligible surface groups) accumulate at the EDL, the electrode is regarded to have stored charge through the NFC mechanism. It is non-faradaic because ideally such an electrostatic interaction between the accumulated ions and the carbon electrode surface does not involve the transfer of electrons crossing the EDL, i,e. the electrode-electrolyte interface. CF storage is also known as pseudocapacitance and has been attributed to the transfer of valence electrons delocalized over an appreciably wide range of energy levels (partial delocalization). ${ }^{2,3}$ It should be pointed out that the aforementioned capacitive storage mechanisms (i.e. NFC and CF) are all typified by rectangular cyclic voltammograms $(\mathrm{CVs})$ and triangular galvanostatic charge-discharge (GCD) plots. ${ }^{2}$ Conversely, NCF storage originates from the transfer of localized valence electrons at a specifically fixed energy level, resulting in peak shaped CVs in line with the Nernst equation and features of rechargeable battery electrode materials. ${ }^{2,4}$

It is worth pointing out that $\mathrm{CF}$ and $\mathrm{NCF}$ are both faradaic in nature and hence have some similarities. The currents on the CVs of both $\mathrm{CF}$ and NCF materials are proportional to the potential scan rates, and will change polarity (or flowing direction) when the potential scan changes its direction. The main difference is in the shape of the CV which is rectangular for CF but peak-shaped for NCF. This is because the charge transfer process in a NCF material involves localized valence electrons, and is thus governed by the Nernst law in principle. However, the charge transfer reaction in a CF material, as mentioned above, is undertaken by delocalized valence electrons as those in semiconductors.

Within an appropriate range of applied electrode potentials, faradaic storage usually arises from charge transfer reactions in the

żE-mail: chuang.peng@whu.edu.cn; george.chen@nottingham.ac.uk redox active materials confined on the electrode such as olivines e.g. $\mathrm{LiFePO}_{4}$ on the electrode. It may however also result from the socalled redox electrolyte that refers usually to a conventional inert electrolyte containing dissolved redox species (DRS), e.g. $\mathrm{Fe}(\mathrm{CN})_{6}{ }^{3-}$ / $\mathrm{Fe}(\mathrm{CN})_{6}{ }^{4-}$ in an aqueous electrolyte. The latter has become popular in recent years to increase the energy storage capacity of carbon-based EDL capacitors. Examples of DRS that have been tested in EDL capacitors include quinonoids, ${ }^{5,6}$ transition metal cations, ${ }^{7-10}$ halide anions, ${ }^{11-14}$ thiocyanates, ${ }^{15}$ and viologens. ${ }^{16-18}$

Some beneficial properties of the DRS as listed and explained below are crucial for effective and efficient coupling with an EDL electrode.

(1) Reversibility of the redox reaction is of great importance because a more reversible reaction can lead to higher charge and energy efficiency of the device.

(2) Solubility of the DRS in the electrolyte should be as high as possible to maximize the storage capacity from the additional charge obtainable.

(3) Potential of the DRS should be as close as possible to the limit of the electrolyte potential window so that the cell working voltage and hence energy capacity can be maximized.

(4) Specific interactions of the product of the charging reaction of the DRS with the EDL electrode (e.g. chemical and electrostatic adsorption, or coating or deposition due to poor solubility) may help retain the product in the electrode, minimising energy loss and self-discharge of the cells due to the redox shuttling between the positive electrode (positrode) and negative electrode (negatrode). ${ }^{19}$

(5) The signs of charge on an ionic DRS and its electrode reaction product should better be the same, e.g. $\mathrm{I}^{-}$and $\mathrm{I}_{3}{ }^{-}$, and opposite to that of the electrode, i.e. cations for negatrode and anions for positrode, to ensure favorable electrostatic interactions.

It is necessary to point out that adoption of the aforementioned properties for DRS selection is not mandatory in the design of practical cells with redox electrolytes. For example, despite criterion (5) above, the cationic redox couple $\mathrm{Ce}^{3+} / \mathrm{Ce}^{4+}$ was used to work with an 
appropriate positrode which has a sufficiently large overpotential for water oxidation and can accommodate the redox reaction at very positive potentials. $^{20}$

A commonly expected issue related with using redox electrolyte in supercapacitors is the shuttling of the redox couple between the positrode and negatrode, which can in principle be mitigated by using an ion-selective membrane. Generally, such membranes have been shown to be effective in reducing self-discharge in supercapacitors using redox electrolytes. ${ }^{21}$ Membranes have also been adopted as a means of extending the maximum charging voltage (MCV) of the so called bi-electrolyte EDL capacitors in which both acidic and alkaline electrolytes are used. The use of a membrane helps compartmentalize the cell, thus enabling each $\mathrm{E} \mid \mathrm{E}$ interface of the positrode and negatrode to operate within their capacitive potential ranges (CPRs). ${ }^{22}$ Such bi-electrolyte cells can also incorporate DRS at one $\mathrm{e}^{23}$ or both ${ }^{24}$ the $E \mid E$ interface(s) to further enhance the charge capacity.

The presence of DRS in the electrolyte of a supercapacitor can increase the charge storage capacity, but this does not always mean an increase in the energy storage capacity. For example, some DRS have electrode potentials that are located in the middle range of the electrochemical window of water. Consequently, aqueous supercapacitors using such DRS tend to have an increased amount of charge stored at low cell voltages, which is of little benefit to increasing the energy capacity.

In this report, we assess the device characteristics of two common halide salts, KI and $\mathrm{KBr}$, to shed some light on this frequently encountered feature (charge storage at low cell voltages), which can be linked to the thermodynamics of the DRS reactions, and the polarization of the AC electrode. Also, using the strategy of capacitance unequalization to adjust the polarizations of electrodes is shown to be effective in maximizing energy storage capacity, and crucial to avoid excessively oversizing the counter-electrode in the design of practical supercapacitors with DRS.

\section{Experimental}

The electrode material used was an activated carbon (AC) powder (YEC-8A, Fuzhou Yihuan Carbon Co. China) with the BrunauerEmmet-Teller (BET) specific surface area (SSA) of ca. $1898.0 \mathrm{~m}^{2} / \mathrm{g}$ as measured on the ASAP Micrometrics 2020 Physisorption Analyser. For electrode preparation, the AC powder was mixed with carbon black (BP2000, Cabot USA) and polytetrafluoroethylene (PTFE, 60\% wt in water, Sigma-Aldrich UK) in a weight ratio of 90:5:5, with ethanol as the dispersing medium. The obtained slurry was stirred at $70^{\circ} \mathrm{C}$ to evaporate ethanol, producing a paste that was roll-pressed (on a DG 200L Roll Press, MAX China) into a blanket which was dried at $120^{\circ} \mathrm{C}$ for 12 hours. The dried blanket was cut or punched, weighed (Sartorius microbalance, $\pm 0.01 \mathrm{mg}$ ), and die pressed under a force of 2 tonnes (aided by little drops of ethanol to enhance lubrication) into cylindrical pellets (diameter: 6 or $13 \mathrm{~mm}$ ). The pressed pellets were further dried at $80^{\circ} \mathrm{C}$ in air for at least 10 hours.

The electrode mass in the prototype cells was $15.00 \pm 0.01 \mathrm{mg}$, and this was used as the baseline for balancing the masses of the electrodes according to the capacitance unequalization strategy. ${ }^{25,26}$ For example, a ratio of 2:1 means an electrode mass ratio of ca. $30.00 \mathrm{mg}: 15.00$ mg. Pressed pellets used in cell fabrication thus had an areal mass loading of at least $11.30 \mathrm{mg} / \mathrm{cm}^{2}$ and a thickness ranging from 240 to $280 \mu \mathrm{m}$, depending on the mass.

Titanium current collectors (thin foils) were used for the fabrication of the 2-electrode Swagelok-type cell without electrode potential monitoring. Moreover, a T-shaped Swagelok cell with a reference electrode (standard calomel electrode, SCE, or silver and silver chloride electrode, $\mathrm{Ag} / \mathrm{AgCl}$ ) and titanium current collectors was used both for electrode characterization in the 3-electrode cell, and also for monitoring the potential of the electrodes in the 2-electrode cell. In all the cells fabricated, the electrolyte volume was controlled so that the contribution from the DRS in the electrolyte to the electrode and cell performance metrics could be quantitatively evaluated. ${ }^{16,19}$ This control of electrolyte volume was done by weighing the mass of the soaked electrodes and separator to ascertain the volumes absorbed, and then adding a specific volume of electrolyte to obtain equal volumes of electrolytes in the cells. In the 3-electrode cell, the working electrode was $6.0 \mathrm{~mm}$ in diameter and ca. $5.00 \mathrm{mg}$ in mass, whereas the counter electrode was of the same material but with a larger diameter of $15.0 \mathrm{~mm}$ and a greater mass of ca. $30.00 \mathrm{mg}$.

Two different types of 2-electrode cell were studied in this work. The first was a conventional cell with the configuration of (-) AC I $\mathrm{KBr}$ or $\mathrm{KI} \mid \mathrm{AC}(+)$, whilst the other was a bi-electrolyte cell with the configuration of (-) AC I negalyte (e.g. $2.0 \mathrm{~mol} / \mathrm{L} \mathrm{KOH}$ ) II posilyte (e.g. $2.0 \mathrm{~mol} / \mathrm{L} \mathrm{KI}) \mid \mathrm{AC}(+)$, where posilyte and negalyte refer to the electrolyte in contact with the positrode and negatrode, respectively. A solution of $2.0 \mathrm{~mol} / \mathrm{L} \mathrm{KOH}$ was used as the negalyte in the bi-electrolyte cell because $\mathrm{KOH}$ can negatively shift the potential for hydrogen evolution, leading to a relatively wide CPR at negative potential scans. ${ }^{22,23}$ These two cells were prepared in a similar manner without excess electrolyte. The separator membrane used was one layer of glassy paper (GF/D, Whatman) in the conventional cell, but two layers for making the bi-electrolyte cell. The membranes were soaked in the electrolyte before use, however, in the bi-electrolyte cell, the electrodes and the separators were soaked in different electrolytes. For the fabrication of the bi-electrolyte cell, after soaking the membranes and the electrodes in the electrolytes, the excess electrolyte in the membranes were gently squeezed out and wiped away, and the two membranes were placed between the positrode and negatrode. The entire cell was assembled without any excess electrolyte. ${ }^{22}$ For monitoring the potential of each electrode in the bi-electrolyte cell, the $\mathrm{Ag} / \mathrm{AgCl}$ reference electrode (a $\mathrm{Ag}$ wire coated with $\mathrm{AgCl}$ ) was placed in-between the two layers of glassy paper. For consistence of discussion, the potential of the $\mathrm{Ag} / \mathrm{AgCl}$ reference was calibrated against a commercial SCE. In this paper, all potential data are reported with reference to the SCE and the conversion was made on the measured potential difference of $0.06 \mathrm{~V}$ between the SCE and $\mathrm{Ag} / \mathrm{AgCl}$.

All electrolytes were bubbled by $\mathrm{Ar}(99.8 \%)$ for at least $20 \mathrm{~min}$. before use for soaking the electrodes or membranes under vacuum for an hour, followed by further Ar bubbling for another $10 \mathrm{~min}$. The separator for the bi-electrolyte cell denoted by II was soaked in a solution of $3.0 \mathrm{~mol} / \mathrm{L} \mathrm{KCl}$. All chemicals used in this work i.e. $\mathrm{KI}$, $\mathrm{KBr}, \mathrm{KCl}$ (purity $>99 \%$ from China Sinopharm) and $\mathrm{KOH}$ (purity $>$ $98 \%$ from Sigma-Aldrich) were used as received.

All electrochemical characterizations were carried out on a Princeton Multichannel Workstation equipped with the PMC-1000 and PMC-2000 modules, and the VersaStudio software package. Equations used for calculation of charge efficiency, capacitance, specific energy and energy efficiency are provided below.

$$
\begin{gathered}
\text { Charge efficiency }\left(\eta_{Q}\right): \quad \eta_{Q}=\frac{Q_{\mathrm{d}}}{Q_{\mathrm{c}}} \times 100 \% \\
\text { Capacitance }(C): \quad C=\frac{Q_{+}+Q_{-}}{2 \Delta E}
\end{gathered}
$$

where $Q_{\mathrm{d}}$ and $Q_{\mathrm{c}}$ are the passing charges when recording the Galvanostatic discharging and charging plot (GCD), $Q_{+}$and $Q_{-}$are those during the positive and negative potential scans for recording a cyclic voltammogram $(\mathrm{CV})$, respectively, and $\Delta E$ is the maximum potential range for recording a rectangular $\mathrm{CV}$, i.e. the capacitive potential range (CPR). It is worth noting that, in principle, $Q_{\mathrm{d}}=Q_{-}$and $Q_{\mathrm{c}}=$ $Q_{+}$for the positrode, but $Q_{\mathrm{d}}=Q_{+}$and $Q_{\mathrm{c}}=Q_{-}$for the negatrode.

In fact, both Eqs. 1 and 2 can also be applied for similar calculations of a two-electrode cell (supercapacitor or supercapattery) by replacing $\Delta E$ in Eq. 2 with the maximum charging voltage (MCV) of the cell, $U_{\max }$. Also, for a cell, there is always $Q_{\mathrm{d}}=Q_{-}$and $Q_{\mathrm{c}}=Q_{+}$ because charging or discharging a cell always, respectively, increases or decreases the cell voltage, $U$. However, the following equations are 

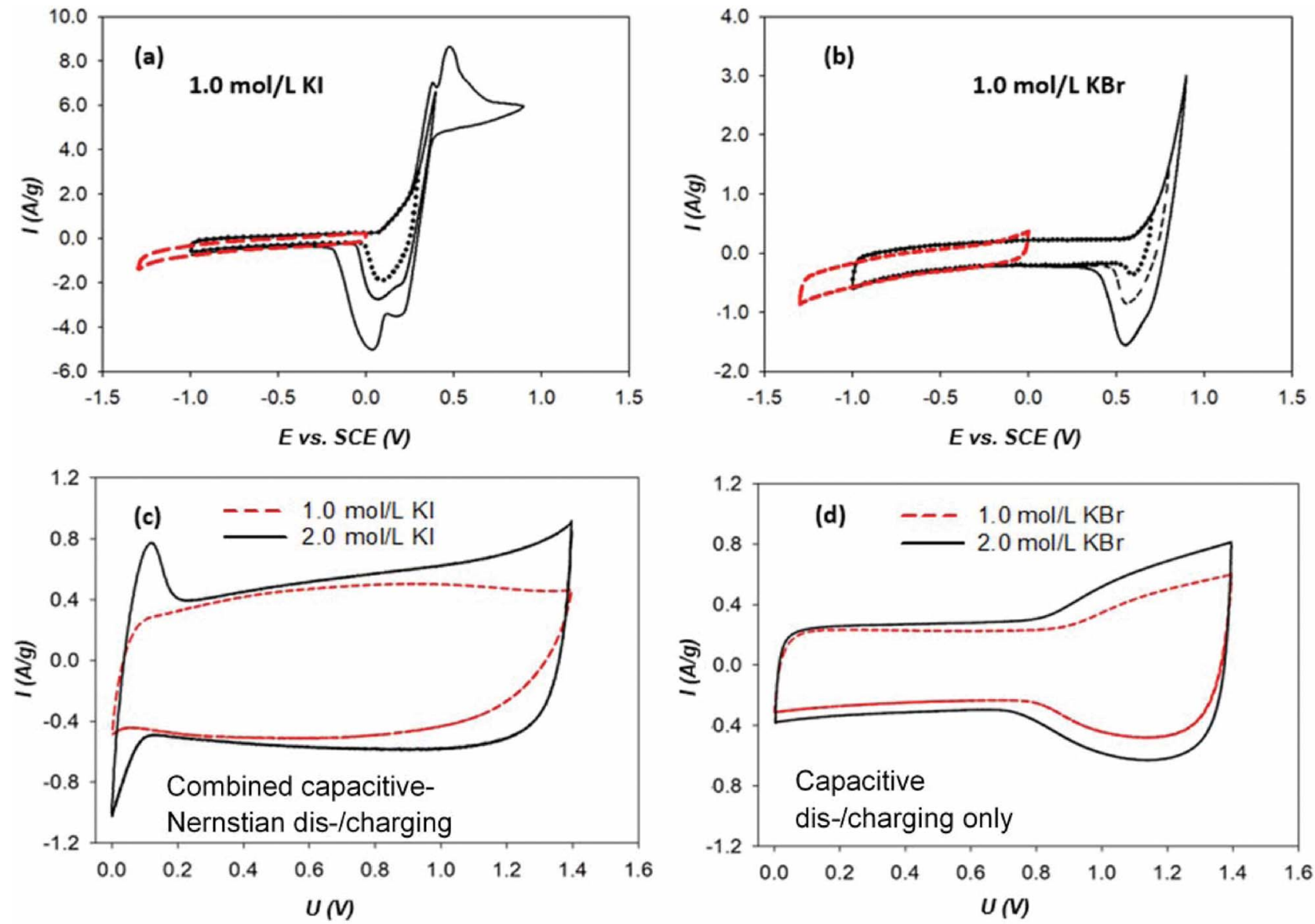

Figure 1. CVs of the AC electrode in (a) $1.0 \mathrm{~mol} / \mathrm{L} \mathrm{KI}$, (b) $1.0 \mathrm{~mol} / \mathrm{L} \mathrm{KBr}$ (scan rate: $1 \mathrm{mV} / \mathrm{s}$ ), and EEM-cells containing 1.0 and $2.0 \mathrm{~mol} / \mathrm{L}$ of (c) $\mathrm{KI}$, and (d) $\mathrm{KBr}$ (scan rate: $5.0 \mathrm{mV} / \mathrm{s}$ )

only applicable to GCDs recorded from a cell.

$$
\begin{gathered}
\text { Specific energy }\left(W_{\mathrm{sp}}\right): W_{\mathrm{sp}}=\int_{U_{\min }}^{U_{\max }} I d U=I \int_{t=0}^{t=t} U_{d}(t) d t \\
\text { Energy efficiency }\left(\eta_{\mathrm{W}}\right): \quad \eta_{\mathrm{W}}=\frac{\int U_{\mathrm{d}}(t) d t}{\int U_{\mathrm{c}}(t) d t} \times 100 \%
\end{gathered}
$$

where $U_{\mathrm{d}}(t)$ and $U_{\mathrm{c}}(t)$ are the cell voltage as a function of the time, $t$, of discharging and charging, respectively, in the GCD measurement of the cell, and $I$ is the mass normalized current (or specific current or current load) against the total mass of active materials on both the positrode and negatrode (i.e. $m_{+}+m_{-}$) in the cell with the unit in $\mathrm{A} / \mathrm{g}$ (or $\mathrm{mA} / \mathrm{g}$ ).

\section{Results and Discussion}

Electrochemical characterization of activated carbon electrode in $\mathbf{K I}$ and $\mathbf{K B r}$.-Cyclic voltammograms (CVs) of the AC electrode in the electrolytes of $1.0 \mathrm{~mol} / \mathrm{L} \mathrm{KI}$ and $1.0 \mathrm{~mol} / \mathrm{L} \mathrm{KBr}$ are shown in Figures $1 \mathrm{a}$ and $1 \mathrm{~b}$, respectively. The $\mathrm{CVs}$ of $\mathrm{AC}$ in $1.0 \mathrm{~mol} / \mathrm{L} \mathrm{KI}$ from -1.40 to $0.90 \mathrm{~V}$ vs. SCE shows the expected full feature of the anodic oxidation of $\mathrm{I}^{-}$into $\mathrm{I}_{2}+\mathrm{I}_{3}{ }^{-}$and their further oxidation. ${ }^{27}$ However, within the same potential range, the $\mathrm{CVs}$ recorded in $1.0 \mathrm{~mol} / \mathrm{L} \mathrm{KBr}$ indicated only the oxidation of $\mathrm{Br}^{-}$to $\mathrm{Br}_{2}+\mathrm{Br}_{3}^{-}$, but their further oxidation did not occur. This difference is actually expected because the oxidation potentials of $\mathrm{Br}^{-}$and $\mathrm{Br}_{2}+\mathrm{Br}_{3}{ }^{-}$are more positive than those of $\mathrm{I}^{-}$and $\mathrm{I}_{2}+\mathrm{I}_{3}{ }^{-}$. It should be mentioned that this potential window from -1.40 to $0.90 \mathrm{~V}$ was selected to enable the faradaic reactions from the dissolved halide anions, but to avoid those from carbon and/or water.

According to both Figs. $1 \mathrm{a}$ and $1 \mathrm{~b}$, from 0 to $-1.40 \mathrm{~V}$, the charge storage mechanism at the carbon/halide interface is due to the EDL capacitance. The $\mathrm{CVs}$ indicate $\mathrm{I}^{-}$ion oxidation starting at potentials slightly above ca. $0.03 \mathrm{~V}$. This is in contrast with the $\mathrm{CVs}_{\mathrm{s}}$ of $\mathrm{Br}^{-}$ion showing dominantly EDL storage until ca. $0.60 \mathrm{~V}$, before commencing $\mathrm{Br}^{-}$oxidation.

The oxidation of halide ions at potentials of the current peaks on the CVs are in line with thermodynamic expectation. However, the contribution of these halide ions, particularly $\mathrm{Br}^{-}$at positive potentials up to ca. $0.50 \mathrm{~V}$ as shown in Fig. 1b, to EDL charging of the $\mathrm{AC}$ electrode before the occurrence of halide oxidation, is also significant.

The highly potential-dependent behavior of the $\mathrm{Br}^{-}$and $\mathrm{I}^{-}$ions as revealed by the CVs in Figs. 1a and $1 \mathrm{~b}$ should affect the charge storage performance of the supercapacitor with two AC electrodes. Thus, two electrode cells with equal electrode mass (EEM) were fabricated and studied. Figs. 1c and 1d show the CVs of the EEM cell with KI and $\mathrm{KBr}$, respectively. It can be seen that the cell with $1.0 \mathrm{~mol} / \mathrm{L}$ $\mathrm{KI}$ exhibited small current peaks whilst the cell with $2.0 \mathrm{~mol} / \mathrm{L} \mathrm{KI}$ displays marked peaks at low cell voltages near $0 \mathrm{~V}$. On the contrary, the cell with $\mathrm{KBr}$ showed large currents at cell voltages higher than $0.70 \mathrm{~V}$. Also, it can be noticed that the capacitive currents in KI are about twice of that in $\mathrm{KBr}$, whilst the total amount of charge enclosed in the CV is similar in both cases.

In the literature on supercapacitors with $\mathrm{I}^{-}$containing electrolytes, the low voltage peaks were reported to be linked to the type of current collector used, ${ }^{28}$ and could even increase after continuous cycling/floating of the cells. ${ }^{29}$ However, no clear and convincing explanation has been given on how the low cell voltage peaks form, 

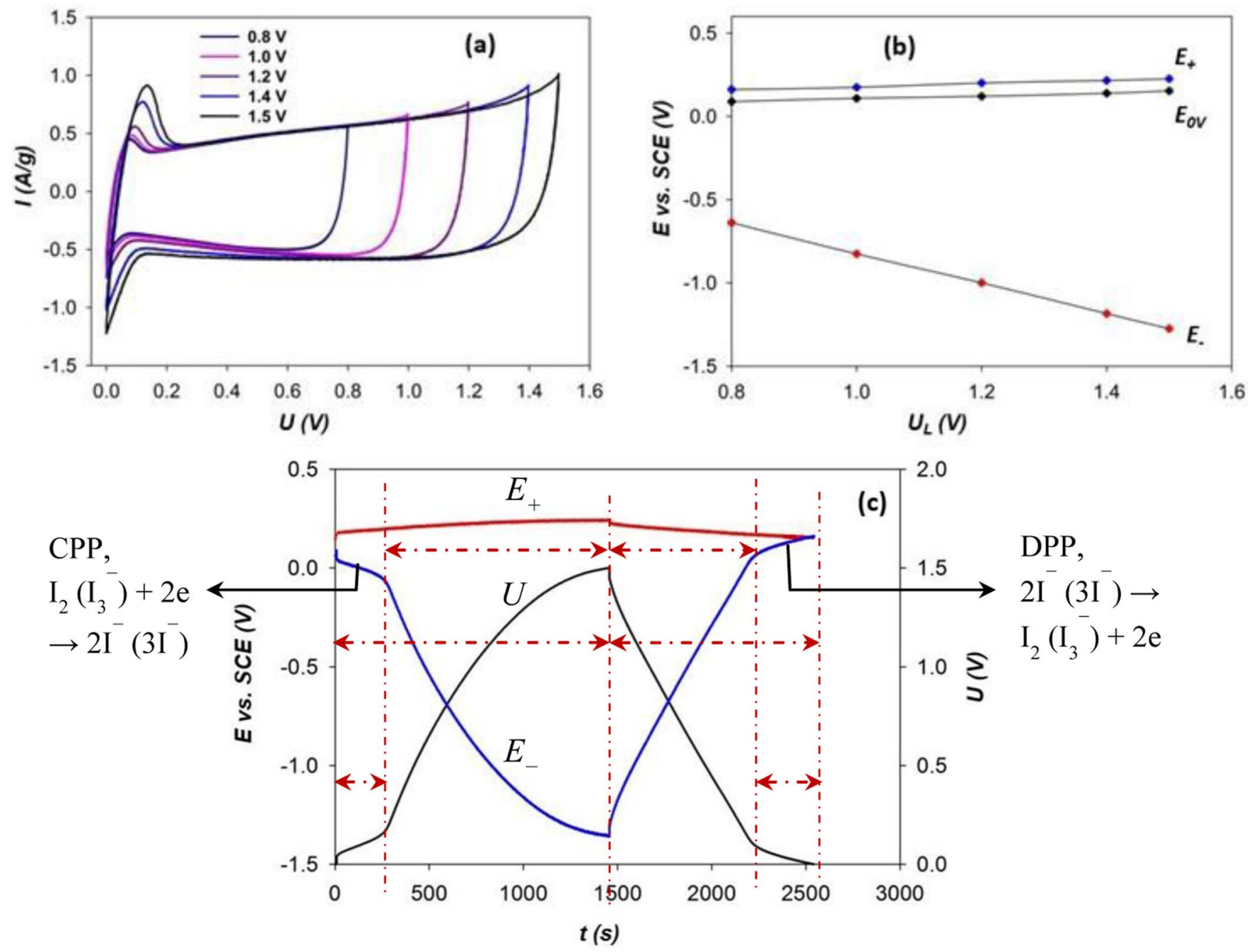

Figure 2. Performance of the EEM cell of AC electrodes with $2.0 \mathrm{~mol} / \mathrm{L} \mathrm{KI}$ : (a) CVs recorded at $5.0 \mathrm{mV} / \mathrm{s}$ with different upper limits of cell voltage ( $U_{\mathrm{L}}$ ), (b) plots of the positrode $\left(E_{+}\right)$, negatrode $\left(E_{-}\right)$and zero voltage $\left(E_{0 \mathrm{~V}}\right)$ potentials vs $U_{L}$ with data extracted from the GCD plots of $U, E_{+}$and $E_{-}$, recorded at a current load of $0.1 \mathrm{~A} / \mathrm{g}$, and (c) GCD plots of $U, E_{+}$and $E_{-}$, with $U_{L}=1.50 \mathrm{~V}$ and current load $=0.1 \mathrm{~A} / \mathrm{g}$.

and their correlation with the experimental conditions, such as the upper cell voltage limit of charging and the concentration of $\mathrm{I}^{-}$. This knowledge gap in the existing literature warrants further analysis and discussion.

As shown in Fig. 1c, the low voltage peaks are merely visible on the $\mathrm{CV}$ recorded in $1.0 \mathrm{~mol} / \mathrm{L} \mathrm{KI}$, but quite marked on that in $2.0 \mathrm{~mol} / \mathrm{L} \mathrm{KI}$. In Fig. 2a, the CVs recorded in $2.0 \mathrm{~mol} / \mathrm{L} \mathrm{KI}$ show a clear trend of the low voltage peaks becoming more prominent with increasing the upper limit of the cell voltage. These observations indicate that at higher $\mathrm{I}^{-}$concentrations and charging voltages, the charging reactions were promoted, and more products from charging reactions were accumulated in the cell before discharging. However, both Figs. 1a and 2a suggest that in KI, the conversion between the reactant $\left(\mathrm{I}^{-}\right)$and products $\left(\mathrm{I}_{2}+\mathrm{I}_{3}{ }^{-}\right)$could only occur at low or near zero cell voltages at which the positrode and negatrode potentials, $E_{+}$ and $E_{-}$, must be approaching $E_{0 \mathrm{~V}}$, i.e. the potential of zero voltage $(\mathrm{PZV})$ at which the cell is fully discharged. (Note: PZV is the equal potential of the positrode and negatrode when the cell is fully discharged to $0 \mathrm{~V}$, but it is not necessarily the same as the better known PZC, potential of zero charge.)

Nernstian and double layer features of electrodes in supercapacitors with redox halides.-Fig. $2 \mathrm{~b}$ plots the measured $E_{0 \mathrm{~V}}$, and peak $E_{+}$and $E_{-}$, against the upper cell voltage limit, $U_{L}$, with the data being extracted from GCD experiments as exemplified in Fig. 2c. Compar- ing Fig. $2 \mathrm{~b}$ with Fig. $1 \mathrm{a}$, it can be certain that $E_{0 \mathrm{~V}}$ coincides with the oxidation potential of the $\mathrm{I}^{-}$ion. Thus, the fact that $E_{+}$varied only slightly in parallel with $E_{0 \mathrm{~V}}$ as shown in both Figs. $2 \mathrm{~b}$ and $2 \mathrm{c}$ confirms that charging and discharging the positrode were dominantly undertaken by Nernstian reactions, i.e. the oxidation of $\mathrm{I}^{-}$and the reduction of $\mathrm{I}_{2}+\mathrm{I}_{3}{ }^{-}$, respectively. On the other hand, the small variation of $E_{+}$is strong evidence of very little contribution, if any, resulting from EDL charging and discharging in the positrode because $Q=C \Delta E$ for a capacitive electrode.

On the negatrode, as shown in Fig. 2c, both charging and discharging processes involved EDL (the linear portion at more negative potentials) and Nernstian (the small potential plateaus near $E_{0 \mathrm{~V}}$ ) contributions. This behavior of the negatrode can be explained starting from discharging the negatrode at the negative potential limit (ca. $-1.32 \mathrm{~V}$ in Fig. 2c, blue line) where the negatrode could not oxidize the $\mathrm{I}^{-}$ion, but underwent EDL discharging. When continued discharging caused $E_{-}$to approach $E_{0 \mathrm{~V}}, \mathrm{I}^{-}$oxidation became feasible to produce $\mathrm{I}_{2}+\mathrm{I}_{3}{ }^{-}$, leading to the discharging potential plateau (DPP). Upon charging the cell, $E_{-}$moved negatively away from $E_{0 \mathrm{~V}}$, and enabled the reduction of $\mathrm{I}_{2}+\mathrm{I}_{3}{ }^{-}$that were generated from $\mathrm{I}^{-}$oxidation, corresponding to the charging potential plateau (CPP).

Without considering the influence from the positrode, it is expected that the total amount of $\mathrm{I}_{2}+\mathrm{I}_{3}{ }^{-}$in the negatrode available for charging should be the same as or less than (considering diffusion of 

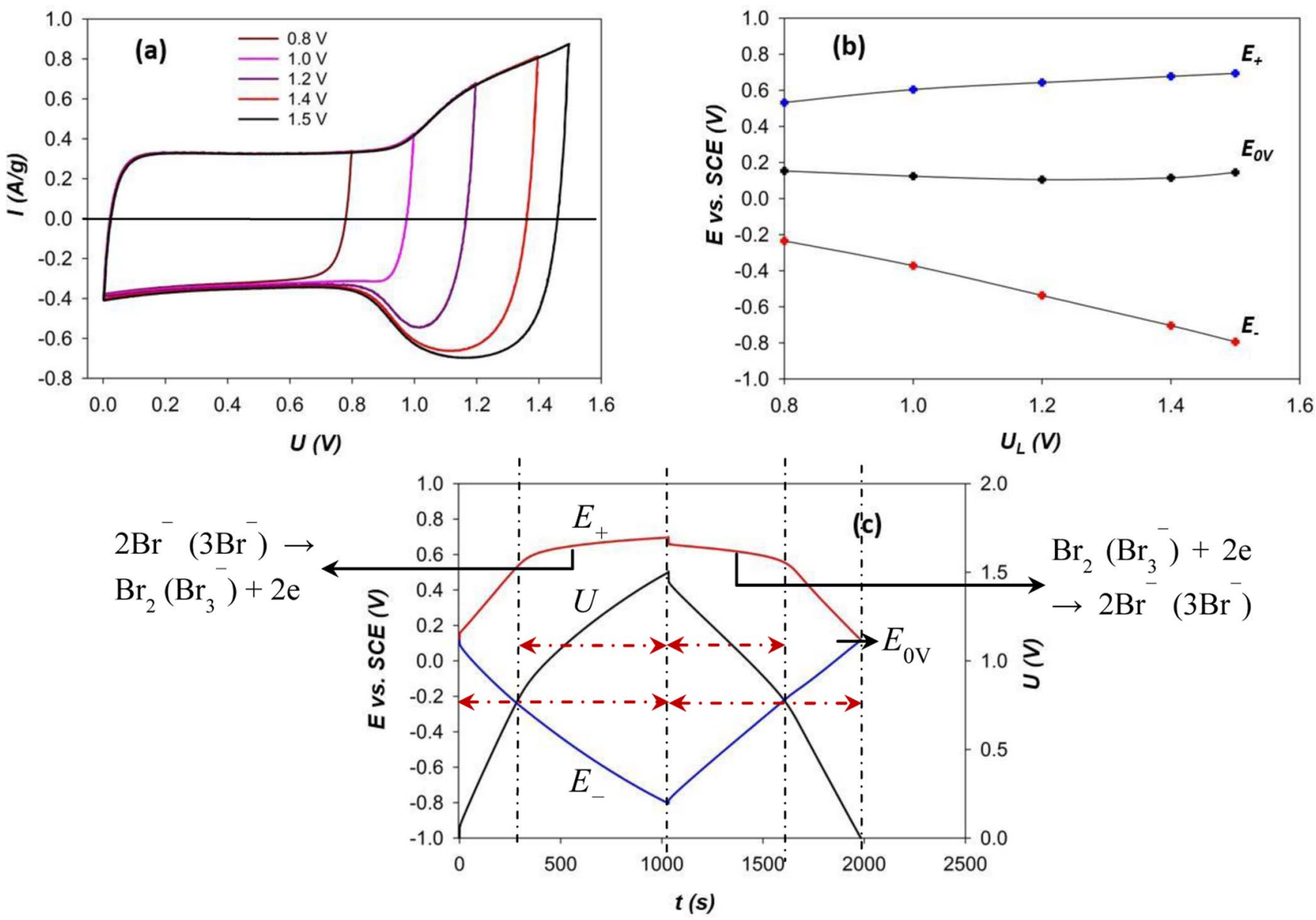

Figure 3. Performance of the EEM cell of AC electrodes with $2.0 \mathrm{~mol} / \mathrm{L} \mathrm{KBr}$ : (a) $\mathrm{CVs}$ recorded at $5.0 \mathrm{mV} / \mathrm{s}$ with different upper limits of cell voltage ( $U_{\mathrm{L}}$ ), and (b) plots of the positrode $\left(E_{+}\right)$, negatrode $\left(E_{-}\right)$and zero voltage $\left(E_{0 \mathrm{~V}}\right)$ potentials vs $U_{L}$ with data extracted from the GCD plots of $U, E_{+}$and $E_{-}$, recorded at a current load of $0.1 \mathrm{~A} / \mathrm{g}(\mathrm{c}) \mathrm{GCD}$ plots of $U, E_{+}$and $E_{-}$, with $U_{L}=1.50 \mathrm{~V}$ and current load $=0.1 \mathrm{~A} / \mathrm{g}$.

$\mathrm{I}_{2}+\mathrm{I}_{3}{ }^{-}$into the bulk electrolyte and the electrostatic repulsion between the negatrode and anions) that generated from $\mathrm{I}^{-}$oxidation at the immediate last stage of discharging the negatrode. This expectation seems to agree with the fact that the length (charge) ratio of DPP/CPP on the GCD plot of the negatrode in Fig. 2c is ca. 1.24. Similar DPP/CPP ratios were obtained from other GCD plots recorded on the negatrode in the KI electrolytes.

The DPP/CPP ratio being larger than 1 is an interesting finding because it seems to agree with that the majority, if not all, of $\mathrm{I}_{2}+$ $\mathrm{I}_{3}{ }^{-}$in the vicinity of negatrode were generated in or at the negatrode, instead of coming from the positrode via the so-called redox shuttling. If so, it is then expected that on the positrode the charges, $Q_{\mathrm{c}}$ and $Q_{\mathrm{d}}$, passed in the charging (oxidation of $\mathrm{I}^{-}$) and discharging (reduction of $\mathrm{I}_{2}+\mathrm{I}_{3}{ }^{-}$) processes, respectively, should be the same or very close. In other words, the charge efficiency of the positrode, $Q_{\mathrm{d}} / Q_{\mathrm{c}}$, should be close to $100 \%$. However, the charge efficiency derived from the GCD of the positrode in Fig. 2c is only $73.1 \%$, which is evidence of a significant part of $\mathrm{I}_{2}+\mathrm{I}_{3}{ }^{-}$generated in the positrode during charging was not recovered during discharging. A possible fate for the lost $\mathrm{I}_{2}+\mathrm{I}_{3}{ }^{-}$from the positrode was that they diffused into the electrolyte, and then were reduced on the negatrode as discussed below.

The above-mentioned experimental finding and analysis of the charging and discharging reactions on both the positrode and negatrode suggest that the conversion between $\mathrm{I}^{-}$and $\mathrm{I}_{2}+\mathrm{I}_{3}{ }^{-}$occurred in both electrodes. A particular point to note is that the reduction of $\mathrm{I}_{2}+\mathrm{I}_{3}{ }^{-}$, if present in the electrolyte, should have continued on the negatrode at potentials more negative than that of the DPP, i.e. approx- imately between 0 and $-1.40 \mathrm{~V}$ in Fig. 2c. The reason why this portion of the negatrode GCD plot is apparently capacitive is because at such negative potentials, reduction of $\mathrm{I}_{2}+\mathrm{I}_{3}{ }^{-}$must be under diffusion control, giving rise to a current that could be constant if the $\mathrm{I}_{2}+\mathrm{I}_{3}{ }^{-}$ concentration in the electrolyte remains approximately the same. This understanding agrees well with the fact that the charge efficiency as derived from the apparent capacitive portions of the negatrode GCD plot is as low as $65.1 \%$, which is obviously the main cause for the fairly low overall charge efficiency of $74.1 \%$ as derived from all the GCD plots in Fig. 2c.

It was also found that the overall cell charge efficiency decreased with increasing the charging cell voltage. For example, the overall charge efficiency was $>90 \%, 83.3 \%, 74.1 \%$ when the charging cell voltage was $1.00,1.20$ and $1.40 \mathrm{~V}$, respectively. This is understandable because at higher charging cell voltages, more $\mathrm{I}_{2}+\mathrm{I}_{3}{ }^{-}$were produced in the positrode, and hence more diffused to and underwent reduction at the negatrode, leading to lower charge efficiency.

While the above discussion leads to a conclusive confirmation of the occurrence of redox shuttling of $\mathrm{I}_{2}+\mathrm{I}_{3}{ }^{-}$between the positrode (charging) and negatrode (discharging), the question is why $\mathrm{I}_{2}+\mathrm{I}_{3}{ }^{-}$ did not all remain in the positrode, but part of $\mathrm{I}_{2}+\mathrm{I}_{3}{ }^{-}$diffused into the electrolyte. Whilst there could be some causes such as pore size and chemical interactions that may affect the retention of $\mathrm{I}_{2}+$ $\mathrm{I}_{3}{ }^{-13,16}$ it is worth noting that the positrode potential did not increase significantly during charging and discharging, as shown in Figs. $2 b$ and 2c. It suggests that electrostatic interaction did not help retain $\mathrm{I}_{2}$ $+\mathrm{I}_{3}{ }^{-}$in the positrode, even at high cell voltages. This means two possibilities. 
Firstly, because $I_{2}$ is neutral in terms of electric charge, its retention in the positrode could not be affected by the potential change but more controlled by chemical potential, particularly concentration gradient that is responsible for diffusion. Secondly, as shown in Figs. $2 b$ and $2 \mathrm{c}$, the positrode potential and its increase during charging were too small to enhance the retention of $\mathrm{I}_{3}{ }^{-}$in the positrode. Thus, diffusion of $\mathrm{I}_{3}{ }^{-}$away from the positrode could also occur. More results and discussion on the shuttling of $\mathrm{I}_{2}+\mathrm{I}_{3}{ }^{-}$will be given later.

Unlike in $\mathrm{KI}$, the cell CVs and GCDs recorded in $\mathrm{KBr}$ presented very different shapes as shown in Figs. 1d, 3a and 3c. The first difference is the absence of the low cell voltage peaks on the CVs. This observation is reflected by the absence of low voltage plateaus on the GCD of the negatrode in Fig. 3c. According to the analysis and discussion above on the $\mathrm{CV}$ and $\mathrm{GCD}$ of $\mathrm{KI}$, these features are indicative of little or no redox shuttling of $\mathrm{Br}_{2}+\mathrm{Br}_{3}{ }^{-}$as generated from oxidation of $\mathrm{Br}^{-}$in the positrode.

The other difference is the appearance of broad current waves at high voltages, i.e. 0.80 to $1.40 \mathrm{~V}$, on the $\mathrm{CVs}$ as expected from oxidation of $\mathrm{Br}^{-}$to $\mathrm{Br}_{2}+\mathrm{Br}_{3}^{-}$and the reversed process during the forward and backward voltage scans, respectively. The corresponding positrode GCD also showed clearly the potential plateaus of the Nernstian feature above the capacitive slopes, which were absent on the positrode GCD of KI. The negatrode GCD in $\mathrm{KBr}$ showed only the capacitive slopes. These GCD features are in agreement with those of the CVs, and support the claim of oxidation of $\mathrm{Br}^{-}$to $\mathrm{Br}_{2}+\mathrm{Br}_{3}{ }^{-}$, but little or no redox shuttling of $\mathrm{Br}_{2}+\mathrm{Br}_{3}{ }^{-}$.

A third difference can be seen by comparing between Figs. 1c and $1 \mathrm{~d}$, and also between Figs. $2 \mathrm{a}$ and $3 \mathrm{a}$. The capacitive currents $(<0.40 \mathrm{~A} / \mathrm{g}$ in Fig. 3a) on the CVs of $\mathrm{KBr}$ between 0 and $0.80 \mathrm{~V}$ are notably smaller than those $(>0.50 \mathrm{~A} / \mathrm{g}$ in Fig. $2 \mathrm{a})$ on the CVs of KI between 0.20 and $1.40 \mathrm{~V}$. The larger capacitive currents in $\mathrm{KI}$ can be explained by the cell voltage variation being undertaken dominantly by the potential change of the negatrode in KI because the positrode potential varied only slightly under Nernstian control as shown in Figs. $2 b$ and $2 c$. On the same time scale, the wider and hence faster potential change (versus those of both the positrode and negatrode in $\mathrm{KBr}$ ) means a larger current for a dominantly capacitive negatrode.

In fact, the apparently larger capacitive currents in $\mathrm{KI}$ could be also partly due to redox shuttling of $\mathrm{I}_{2}+\mathrm{I}_{3}{ }^{-}$. The negatrode in $\mathrm{KBr}$ was only capable of EDL charging and discharging, but in KI underwent both EDL and Nernstian charging (reduction of $\mathrm{I}_{2}+\mathrm{I}_{3}{ }^{-}$, partly shuttled from the positrode under diffusion control), contributing to larger charging currents. Upon discharging the negatrode, however, oxidation of $\mathrm{I}^{-}$could not occur until the potential reached near $\mathrm{E}_{0 \mathrm{~V}}$. The consequence was a lower charge efficiency. Indeed, the overall charge efficiency was $94.2 \%$ in $\mathrm{KBr}$ as derived from Fig. 3c, in contrast to $74.1 \%$ in KI from Fig. 2c. This analysis again suggests insignificant, if any, redox shuttling in $\mathrm{KBr}$.

The CVs and GCDs of the cell deserve more discussion in terms of whether the cell voltage (not the electrode potential) at which the redox reaction occurs may be increased so that redox shuttling can be avoided or minimized, whilst energy capacity can be increased. For the cell containing $2.0 \mathrm{~mol} / \mathrm{L} \mathrm{KBr}$ (cf. Fig. 3), it was noticed that in the course of increasing the cell voltage $(U)$ to the upper limit $\left(U_{L}=\right.$ $1.50 \mathrm{~V})$, the positrode potential also increased from $0.13 \mathrm{~V}\left(=E_{0 \mathrm{~V}}\right)$ to $0.72 \mathrm{~V}$ vs. SCE, experiencing EDL charging only ( 0.13 to $0.62 \mathrm{~V})$, and then mainly Nernstian charging as indicated by the potential plateaus $(0.62$ to $0.72 \mathrm{~V})$. However, for the cell with $2.0 \mathrm{~mol} / \mathrm{L} \mathrm{KI}$, at all cell voltages applied, the positrode exhibited dominant Nernstian charging in a narrow potential range ( 0.16 to $0.23 \mathrm{~V}$ vs SCE, cf. Fig. $2 \mathrm{c})$. In line with the behavior of the positrode, Fig. 3 shows also obviously and understandably that at $U<0.90 \mathrm{~V}$, the cell containing $\mathrm{KBr}$ displayed capacitive features, and the contribution from the redox charging of the electrode only set in when $\mathrm{U}>0.90 \mathrm{~V}$. This observation can be explained from the concept of the unequal electrode capacitance of the cell.

For charge conservation, the amounts of charge passing through the positrode and negatrode must be equal and can be expressed as follows, if both electrodes are capacitive,

$$
Q_{n}=C_{n} \Delta E_{n}=C_{p} \Delta E_{p}=Q_{p}
$$

where $Q, C$ and $\Delta E\left(=E-E_{0 \mathrm{~V}}\right)$ are the total charge, capacitance and applied potential range that is within or the same as the capacitive potential range (CPR) of the electrode, and the subscripts $n$ and $p$ indicate the negatrode and positrode respectively. Note that $E$ is the potential of the negatrode or positrode at an applied cell voltage $U$, and $E_{0 \mathrm{~V}}$ is the equipotential of the positrode and negatrode at $U=0 \mathrm{~V}$, i.e. the potential of zero voltage $(\mathrm{PZV})$. Accordingly, provided that $E_{0 \mathrm{~V}}, E_{\mathrm{n}}$ and $E_{\mathrm{p}}$ are within the CPR of the respective electrodes, the maximum charging voltage (MCV) of the cell can be extended through unequalization of electrode capacitances by utilising the following Eq. 5.

$$
\operatorname{MCV}\left(U_{\text {max }}\right)=\Delta E_{p}\left(1+C_{p} / C_{n}\right)
$$

In Eq. 5 , the choice of $\Delta E_{\mathrm{p}}$ is based on the assumption that of the two electrodes, the positrode has the narrower CPR and hence is the voltage determining electrode. Also, Eq. 5 simply means that the polarization of one electrode relative to the other can be adjusted by changing the capacitance ratio of the two electrodes. This reasoning is very important to understand the operation of the EEM cells using $\mathrm{KBr}$, and this would be addressed later.

Referring to Eq. 4, if a redox reaction occurs at the positrode, then $Q_{\mathrm{p}}$ would have two components, namely, $Q_{\mathrm{p}}=Q_{\mathrm{p} 1}+Q_{\mathrm{p} 2}$, where $Q_{\mathrm{p} 1}$ and $Q_{\mathrm{p} 2}$ refer to the EDL and Nernstian contributions, respectively. Obviously, $Q_{\mathrm{p} 1}=m_{\mathrm{p}} C_{\mathrm{sp}} \Delta E_{\mathrm{p}}$, whilst it would be generally correct for $Q_{\mathrm{p} 2}=n F N_{0} V_{0}$, where $N_{0}$ and $V_{0}$ are the concentration and volume of the redox electrolyte in the porous positrode, respectively, $n$ is the number of electron(s) participating in the reaction, and $F$ the Faraday constant $(96,485 \mathrm{C} / \mathrm{mol})$. Thus, the following expression can be established.

$$
Q_{\mathrm{p}}=Q_{\mathrm{p} 1}+Q_{\mathrm{p} 2}=m_{\mathrm{p}} C_{\mathrm{sp}} \Delta E_{\mathrm{p}}+n F N_{0} V_{0}
$$

As a first approximation, $V_{0}$ in Eq. 6 can be considered to be the total volume of electrolyte absorbed into the saturated porous positrode (excluding any excess electrolyte). However, from a practical perspective, because some pores may not be accessible electrochemically, $V_{0}$ could be larger than the volume of accessible pores of the positrode, $V_{\text {pore }}$. Furthermore, $V_{\text {pore }}$ should be fundamentally expressed as a function of the pore size distribution, for example, as obtained from DFT analysis of the physisorption properties of the electrode material.

By substituting Eq. 6 into Eq. 4 , and dividing through by $\Delta E_{\mathrm{p}}$, one can then obtain the following expression,

$$
\frac{Q_{\mathrm{p}}}{\Delta E_{\mathrm{p}}}=m_{\mathrm{p}} C_{\mathrm{sp}}+\frac{n F N_{0} V_{0}}{\Delta E_{\mathrm{p}}} .
$$

Eq. 7 implies that the faradaic component of the charge stored would provide a given amount of charge stored per unit increase in the positrode potential. Of course for this faradaic component to set in, there should be $\Delta E_{\mathrm{p}} \geq E_{\mathrm{N}}-E_{0 \mathrm{~V}}$, where $E_{\mathrm{N}}$ is the electrode potential of the redox couple determined by the Nernst equation. For example, in the $\mathrm{KBr}$ solution, the oxidation of $\mathrm{Br}^{-}$to $\mathrm{Br}_{2}+\mathrm{Br}_{3}{ }^{-}$can be expressed as

$$
(2+\beta) \mathrm{Br}^{-}=\alpha \mathrm{Br}_{2}+\beta \mathrm{Br}_{3}^{-}+2 \mathrm{e}
$$

where $\alpha+\beta=1$. Then, the Nernst equation is given below,

$$
E_{\mathrm{N}}=E^{\mathrm{o}}+\frac{R T}{2 F} \ln \left(\frac{a_{B r_{2}}^{\alpha} a_{B r_{3}^{-}}^{\beta}}{a_{B r^{-}}^{2+\beta}}\right)
$$

where $E^{0}$ is the standard potential for the oxidation of $\mathrm{Br}^{-}$to $\mathrm{Br}_{2}+$ $\mathrm{Br}_{3}{ }^{-}$, and $a$ the activity of the respective redox species in the electrolyte. It should be pointed out that Eq. 9 is simplified, and more rigorous expressions have been derived to explicitly consider the activity as a function of other experimental variables, such as reaction volume and electrolyte components. ${ }^{16}$ 

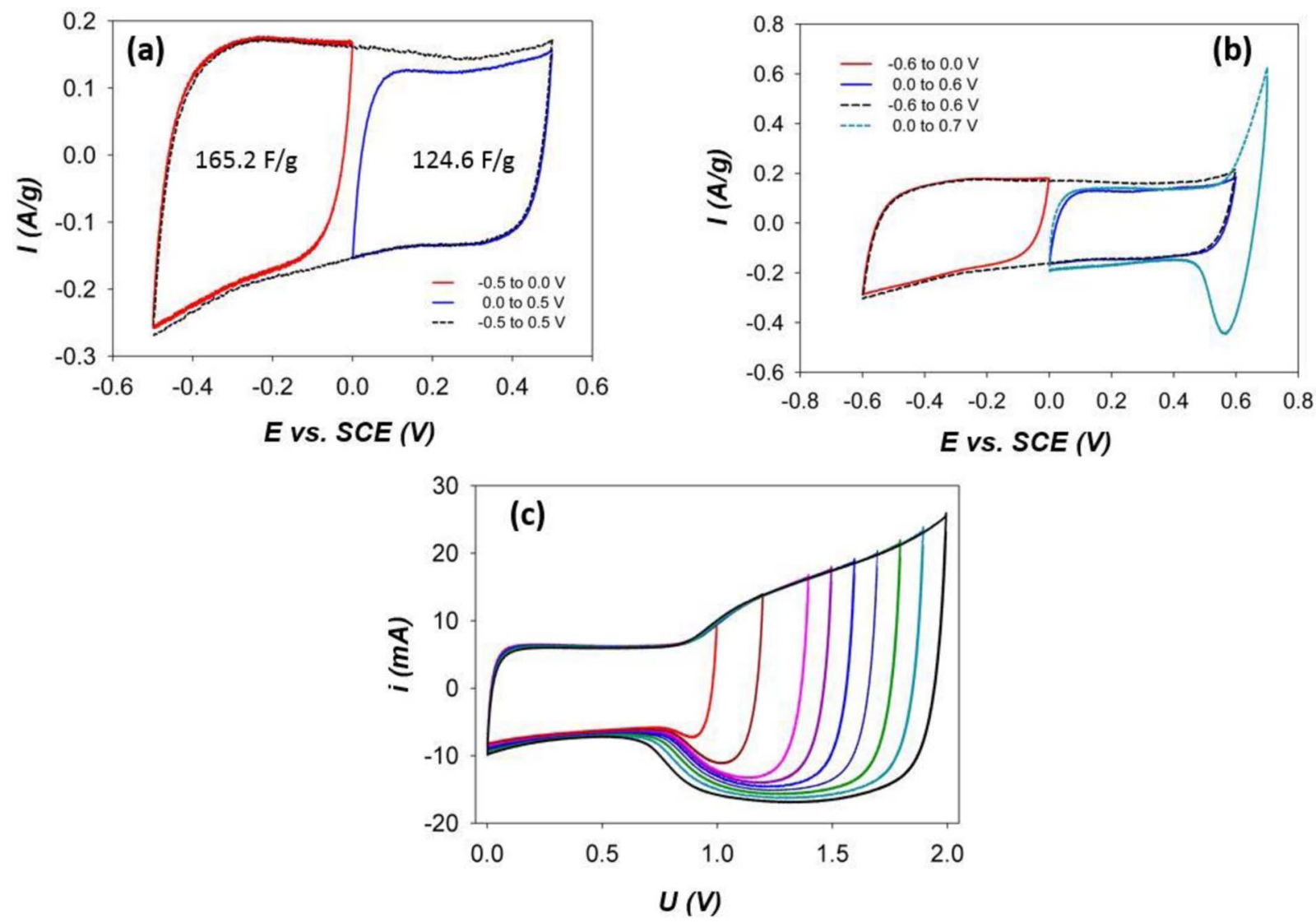

Figure 4. $\mathrm{CVs}$ of the $\mathrm{AC}$ electrode in $1.0 \mathrm{~mol} / \mathrm{L} \mathrm{KBr}$, showing (a) the asymmetry in capacitance in two different potential ranges within the CPR, and (b) the occurrence of the Nernstian process, i.e. oxidation of $\mathrm{Br}^{-}$, at potentials more positive to the CPR. Scan rate: $1.0 \mathrm{mV} / \mathrm{s}$. (c) CVs of the EEM cell of the AC electrodes in $1.0 \mathrm{~mol} / \mathrm{L} \mathrm{KBr}$ recorded with increasing cell voltage limits from 1.00 to $2.00 \mathrm{~V}$. Scan rate: $5.0 \mathrm{mV} / \mathrm{s}$.

The above descriptions of the electrode properties can now be used to explain in detail the properties of supercapacitors with DRS. Figure 4a shows the CVs of the AC electrode in $1.0 \mathrm{~mol} / \mathrm{L} \mathrm{KBr}$ recorded respectively in the potential range from 0 to $0.50 \mathrm{~V}$ and from 0 to $-0.50 \mathrm{~V}$ vs. SCE. The capacitance of the $\mathrm{AC}$ was $124.6 \mathrm{~F} / \mathrm{g}$ when measured between 0 and $0.50 \mathrm{~V}$, but $165.2 \mathrm{~F} / \mathrm{g}$ between 0 and $-0.50 \mathrm{~V}$. This finding implies that in the EEM cell with $\mathrm{KBr}$, as the cell voltage limit is gradually increased, the positrode would be more polarized relative to the negatrode according to Eq. 4, which also agrees with the $E$ vs. $U$ plot in Fig. 3b. Subsequently, when the potential of the positrode reached the value at which the $\mathrm{Br}^{-}$ion is active, its charge storage mechanism attains the Nernstian component, and thus takes on the expression given in Eq. 7.

It is also important to point out that Eq. 5 can be used to approximately predict the cell voltage, $U_{\text {redox }}$ at which the Nernstian contribution could be observed in the EEM cell with $\mathrm{KBr}$. From Fig. $3 \mathrm{c}, \Delta E_{\mathrm{p}}$ can be taken as $0.49 \mathrm{~V}$, i.e. from $0.13 \mathrm{~V}\left(=E_{0 \mathrm{~V}}\right)$ to $0.62 \mathrm{~V}$ vs. SCE, and by taking $C_{\mathrm{p}}=124.6 \mathrm{~F} / \mathrm{g}$, and $C_{\mathrm{n}}=165.2 \mathrm{~F} / \mathrm{g}$ from Fig. 4a, and substituting these data into Eq. 5 , it can be obtained that $U_{\text {redox }}=0.49(1+124.6 / 165.2)=0.86 \mathrm{~V}$ at which the Nernstian contribution to the cell with $\mathrm{KBr}$ would commence. This agrees well with that of $0.90 \mathrm{~V}$ shown in Fig. 1d. Also from the CVs in Fig. 1b, it can be seen that it is possible to extend the voltage of the EEM cell with $\mathrm{KBr}$ to $2.00 \mathrm{~V}$ as shown in Fig. 4c. Such analysis and calculation demonstrate that the electrode thermodynamics of the DRS, and the nature and extent of the electrode polarization determine the observed performance features of the cells.

To describe the occurrence of the current peaks on the CVs at low voltages for the KI cells, it is necessary to assess the position of the $E_{0 \mathrm{~V}}$ of the electrodes in any given supercapacitor with or without DRS. In principle, at an applied $U$ on a given cell, $E_{0 \mathrm{~V}}$ may be linked to the properties of the $\mathrm{E} \mid \mathrm{E}$ interface, but it can still vary considerably from one supercapacitor to another, or even between similar devices with different histories. Also, at $E_{0 \mathrm{~V}}$, there may still be excess charges on the surfaces of the positrode and negatrode, and under the opencircuit conditions, the electrode potentials would readily proceed to assume their respective equilibrium states through a redistribution of these surface charges.

In the situation of the KI cell, what is most striking is that $E_{0 \mathrm{~V}}$ varied between 0.09 and $0.15 \mathrm{~V}$ vs $\mathrm{SCE}$, and was very close to $E_{\mathrm{p}}$ ( 0.16 to $0.23 \mathrm{~V}$ vs SCE) of the positrode where $\mathrm{I}^{-}$and $\mathrm{I}_{2}+\mathrm{I}_{3}{ }^{-}$are all active (see Fig. 2b). However, for the $\mathrm{KBr}$ cell, $E_{0 \mathrm{~V}}$ varied from 0.13 to $0.15 \mathrm{~V}$, and was farther from $E_{\mathrm{p}}(0.44$ to $0.72 \mathrm{~V}$ vs SCE, cf. Figs. $3 \mathrm{~b}$ and $3 \mathrm{c}$ ). Consequently, in the KI cell, the oxidation of $\mathrm{I}^{-}$to $\mathrm{I}_{2}+\mathrm{I}_{3}{ }^{-}$could contribute to the charge storage in both the positrode and negatrode, resulting in the current peaks at low cell voltages. Regarding the $\mathrm{KBr}$ cell, there was absence of the current peaks because $E_{0 \mathrm{~V}}$ was separated far away from the potential range where the $\mathrm{Br}^{-}$to $\mathrm{Br}_{2}+\mathrm{Br}^{-}{ }_{3}$ conversion would occur.

The above findings, analyses and discussions demonstrate that the occurrence of low voltage peaks in $\mathrm{KI}$ is largely due to the negatrode working at potentials near the redox potential for the $\mathrm{I}^{-}$to $\mathrm{I}_{2}+\mathrm{I}_{3}^{-}$ conversion, instead of being indicative of the extent of adsorption of the generated redox species. For instance, it was demonstrated that the products of $\mathrm{I}^{-}$oxidation could strongly adsorb on or interact with an AC positrode. ${ }^{31}$ It was also shown that iodides could adsorb on the carbon electrode more readily than bromides. ${ }^{16}$ Further, a recent report on cells with functionalized carbon nanotubes in an aqueous electrolyte comprising of $0.5 \mathrm{~mol} / \mathrm{L} \mathrm{KBr}$ and $1.0 \mathrm{~mol} / \mathrm{L} \mathrm{Na}_{2} \mathrm{SO}_{4}$, presented high currents at low cell voltages, despite a cation exchange membrane was used in the cell. ${ }^{32}$ However, according to this work, it was highly likely that such cells allowed the negatrode to operate 
at potentials where the redox activity of halide ions could have been invoked.

To gain further understanding on the origin of these low voltage peaks, the performance of a bi-electrolyte cell with different posilyte and negalyte, $(-) \mathrm{AC}|2.0 \mathrm{~mol} / \mathrm{L} \mathrm{KOH}||2.0 \mathrm{~mol} / \mathrm{L} \mathrm{KI}| \mathrm{AC}(+)$, was assembled and analyzed. From Fig. 5a, it can be observed that despite $\mathrm{I}^{-}$and $\mathrm{I}_{2}+\mathrm{I}_{3}{ }^{-}$are active at the positrode in this cell, its current increase occurred at higher cell voltages. Also, Fig. 5b which shows the $E$ vs $U$ plot of this cell suggests that the presence of the membrane kinetically adjusted $E_{0 \mathrm{~V}}$ to a range $(-0.17$ to $-0.24 \mathrm{~V}$ vs SCE) where $\mathrm{I}^{-}$and $\mathrm{I}_{2}+\mathrm{I}_{3}{ }^{-}$could not contribute to the charge storage in the negatrode. Such a design can thus be viewed as "forced confinement" of the redox species, as opposed to the one achieved from a thermodynamically driven interaction between the products of the redox reaction and the AC electrode. Therefore, it is suggested that any procedure that allows $E_{0 \mathrm{~V}}$ to shift away from the potential for the DRS to react at the electrode (in this case the positrode) should help prevent current peaks at low cell voltages. This is particularly important for some organic redox molecules, such as quinonoids and methyl-violet, which could result in devices displaying current peaks at low cell voltages.

Capacitance unequalization and the features of supercapacitors containing $\mathbf{K B r}$.-From a device design perspective, it is also possible to describe the utilization of the products of the DRS reactions from the standpoint of the electrode polarizations. To demonstrate this, UEM cells each containing the same volume of $1.0 \mathrm{~mol} / \mathrm{L} \mathrm{KBr}$ electrolyte, with negatrode to positrode AC mass ratios of (3:4) and (4:3), (1:2) and (2:1), and (1:2.7) and (2.7:1), were tested. Onwards, these cells would be referred to by the mass ratio of the negatrode to positrode. As shown in Fig. 6, it was observed that cells with higher negatrode to
Table I. Cell parameters: $\eta_{Q}$ (charge efficiency), $\eta_{W}$ (energy efficiency), $W_{\mathrm{sp}}$ (specific discharge energy), calculated from the GCD plots in Figure 6, $\pm i$ (applied charge-discharge current), \pm $I$ ( $\pm i$ normalized by the total dry mass, $m_{\mathrm{t}}=m_{+}+m_{-}$, of both electrodes in the cell).

\begin{tabular}{ccccccc}
$m_{-}: m_{+}$ & $\begin{array}{c}m_{\mathrm{t}} \\
(\mathrm{mg})\end{array}$ & $\begin{array}{c}\eta_{\mathrm{Q}} \\
(\%)\end{array}$ & $\begin{array}{c}\eta_{\mathrm{W}} \\
(\%)\end{array}$ & $\begin{array}{c}W_{\mathrm{sp}} \\
(\mathrm{Wh} / \mathrm{kg})\end{array}$ & $\begin{array}{c} \pm i \\
(\mathrm{~mA})\end{array}$ & $\begin{array}{c} \pm I= \pm i / m_{\mathrm{t}} \\
(\mathrm{A} / \mathrm{g})\end{array}$ \\
\hline $1: 1$ & 30.08 & 97.3 & 86.0 & 17.3 & 7.5 & 0.25 \\
$4: 3$ & 35.20 & 98.6 & 84.4 & 20.3 & 8.8 & 0.25 \\
$2: 1$ & 45.20 & 96.9 & 83.7 & 24.1 & 11.3 & 0.25 \\
$2.7: 1$ & 55.60 & 91.3 & 78.7 & 29.0 & 13.9 & 0.25 \\
$3: 1$ & 60.04 & 93.4 & 76.6 & 33.2 & 15.0 & 0.25 \\
$4: 1$ & 75.28 & 95.1 & 79.3 & 30.6 & 18.8 & 0.25
\end{tabular}

positrode mass ratios offered smaller capacitive currents at lower cell voltages, but larger faradaic currents at higher cell voltages, which means more effective utilization of the additional charge from the DRS reactions.

This observation is expected because, according to Eq. 4, a higher positrode capacitance would result in lesser polarization, which consequently limits the utilization of the DRS for charge storage. Fig. 7 shows the GCD plots of the EEM cell (1:1), compared with those of the UEM cells $(4: 3),(2: 1),(2.7: 1),(3: 1)$, and (4:1). In Fig. 7, it can be noticed that the specific discharge energy $\left(W_{\mathrm{sp}}\right)$ increases with increasing the mass of the negatrode, i.e. $(2: 1)>(4: 3)>(1: 1)$. However, the UEM cells $(2.7: 1),(3: 1)$ and $(4: 1)$ did not display this same trend. The charge and energy efficiencies, and the discharge energy of the cells are shown in Table I. Generally, although the cell with mass ratio of (3:1), delivers the highest discharge energy, still its energy efficiency is lower than that of $(2.7: 1)$ and (4:1).
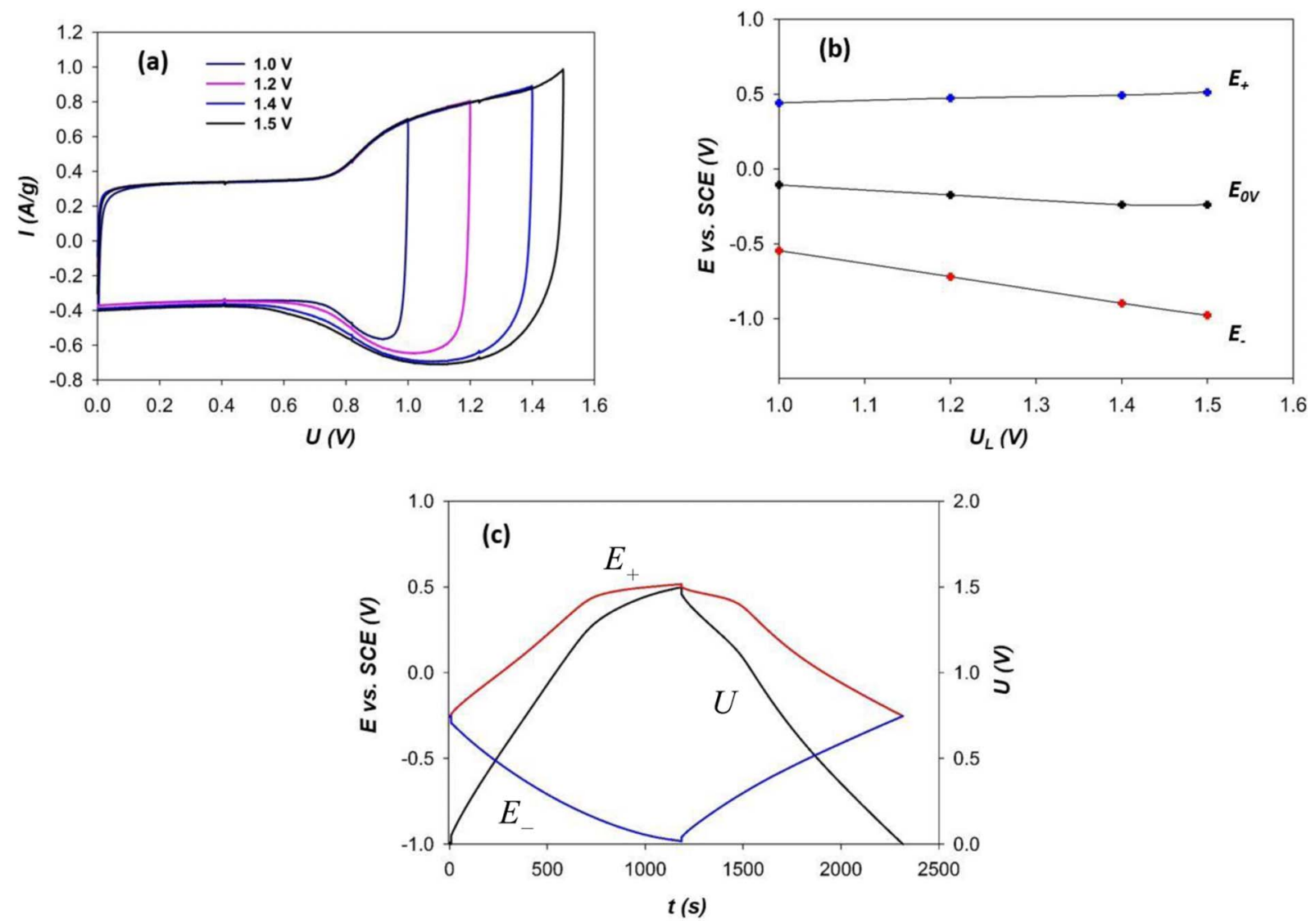

Figure 5. Performance of the EEM bi-electrolyte cell, (-) AC $|2.0 \mathrm{~mol} / \mathrm{L} \mathrm{KOH} \| 2.0 \mathrm{~mol} / \mathrm{L} \mathrm{KI}| \mathrm{AC}(+)$ : (a) CVs recorded at $5.0 \mathrm{mV} / \mathrm{s}$ with different upper limits of cell voltage $\left(U_{\mathrm{L}}\right)$, (b) plots of the positrode $\left(E_{+}\right)$, negatrode $\left(E_{-}\right)$and zero voltage $\left(E_{0 \mathrm{~V}}\right)$ potentials vs $U_{L}$ with data extracted from the GCD plots of $U$, $E_{+}$and $E_{-}$, recorded at $I=0.1 \mathrm{~A} / \mathrm{g}$, and (c) GCD plots of $U, E_{+}$and $E_{-}$, with $U_{L}=1.50 \mathrm{~V}$ and $I=0.1 \mathrm{~A} / \mathrm{g}$. 

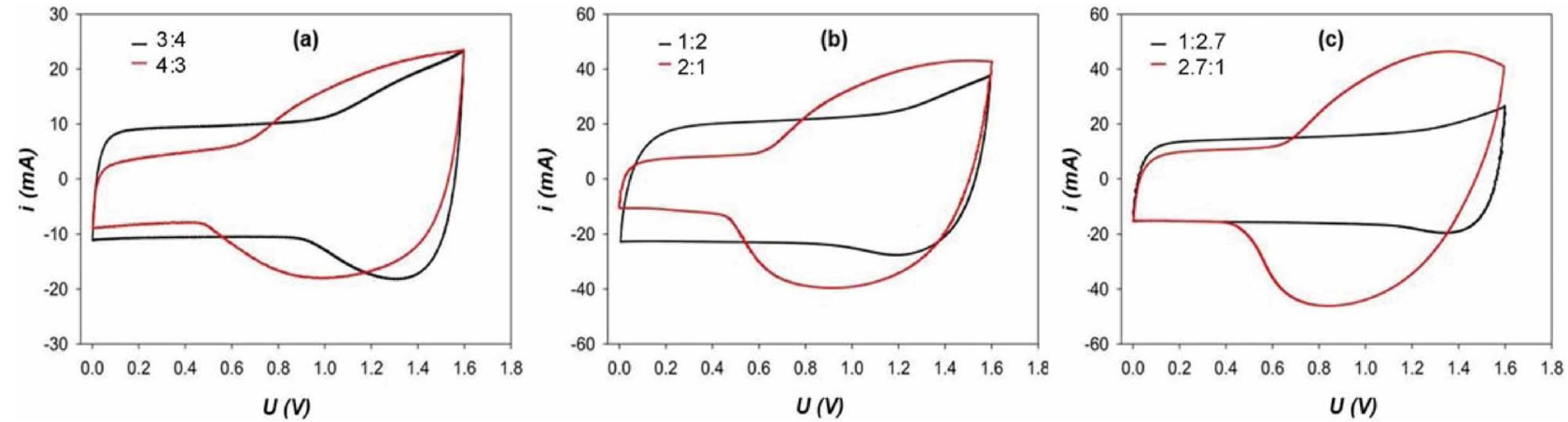

Figure 6. CVs of UEM cells with different negatrode to positrode mass ratios, (a) (3:4) and (4:3), (b) (1:2) and (2:1), and (c) ( 1:2.7) and (2.7:1). Scan rate: 10 $\mathrm{mV} / \mathrm{s}$.

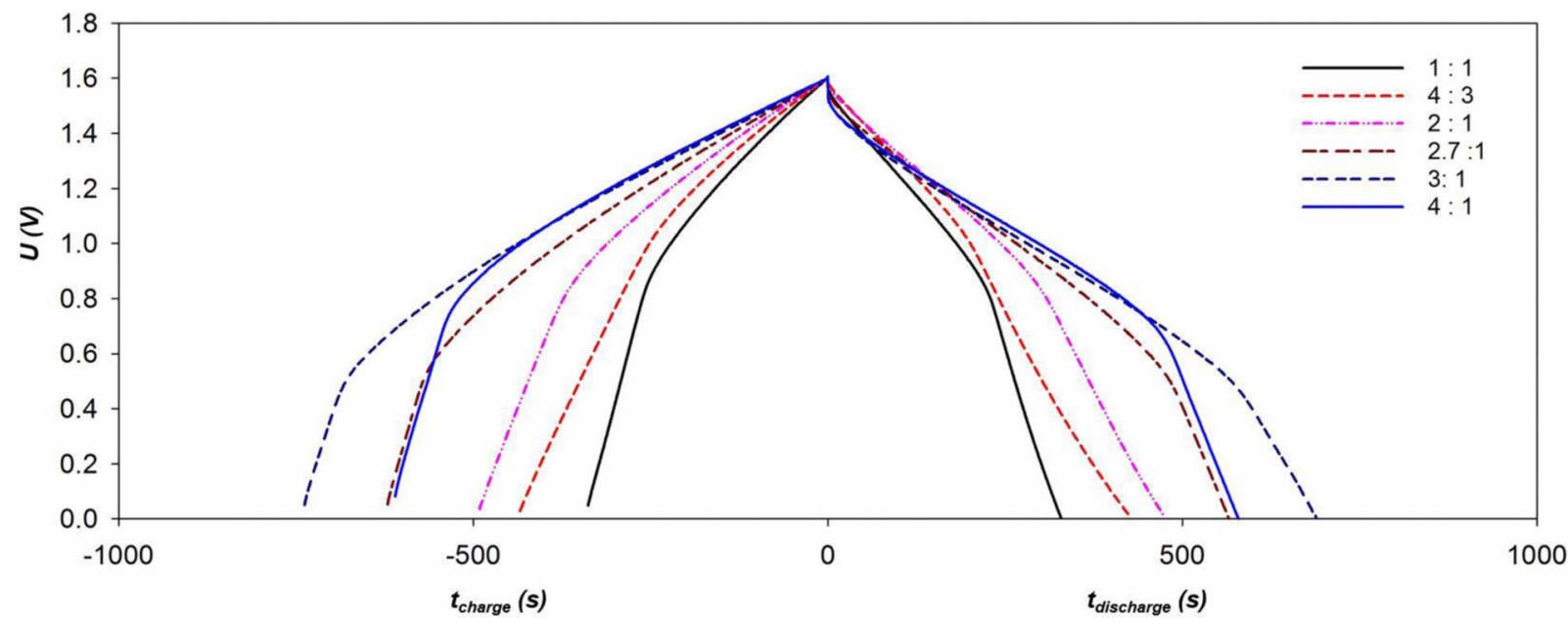

Figure 7. GCD plots comparing the EEM cell (1:1) with other UEM cells with the indicated negatrode to positrode mass ratios. Current load: $0.25 \mathrm{~A} / \mathrm{g}$ (normalized to the total dry mass of active materials on both the positrode and negatrode). All cells had an approximately equal volume of $1.0 \mathrm{~mol} / \mathrm{L} \mathrm{KBr}$ electrolyte.

Moreover, the charge and energy efficiencies of the cell with mass ratio (4:1) is slightly higher than that of the cell with mass ratio $(3: 1)$. These variations in performance metrics with increased negatrode mass generally show that arbitrary oversizing the counter capacitive electrode might not lead to optimal device metrics in some cases.

Regarding other technical aspects of these supercapacitors containing DRS, or supercapatteries, it was recently highlighted that thin electrodes with low mass loadings tended to exaggerate the power performance. ${ }^{33}$ This implies that electrodes such as the ones used herein, i.e. areal density greater than $11.3 \mathrm{mg} / \mathrm{cm}^{2}$ reflect adequately the role in which tortuosity, interfacial resistance etc. would play in supercapacitors with DRS. Additionally, it should be highlighted that although the performance of the bi-electrolyte cell described above was demonstrated to be relatively satisfactory, ${ }^{23}$ still their practical applications might be challenging owing to their rather complicated designs. $^{22}$

\section{Conclusions}

For symmetrical supercapacitors with AC electrodes in aqueous $\mathrm{KI}$ electrolytes, the occurrence of high currents at low cell voltages (near $0 \mathrm{~V}$ ) can be attributed to the conversion between $\mathrm{I}^{-}$and $\mathrm{I}_{2}+$ $\mathrm{I}_{3}{ }^{-}$at both the positrode and negatrode. This is possible when $E_{0 \mathrm{~V}}$ is close to the potential of the $\mathrm{I}^{-}$to $\mathrm{I}_{2}+\mathrm{I}_{3}{ }^{-}$conversion. The shuttling of $\mathrm{I}_{2}+\mathrm{I}_{3}{ }^{-}$between the positrode and negatrode has been confirmed, and is also an influential factor on the low cell voltage current peaks observed on the CVs. The shuttling becomes more significant at higher cell voltages, but can be eliminated by using a bi-electrolyte cell. However, in aqueous $\mathrm{KBr}$ electrolytes, little or no shuttling occurs and the charge efficiency of the cell is also higher, mainly because the potential for the conversion between $\mathrm{Br}^{-}$and $\mathrm{Br}_{2}+\mathrm{Br}_{3}{ }^{-}$is much more positive than $E_{0 \mathrm{v}}$. It is also shown that the $\mathrm{AC}$ electrode in $\mathrm{KBr}$ has slightly higher specific capacitance at potentials between 0 and $-0.50 \mathrm{~V}$ than that between 0 and $0.50 \mathrm{~V}$. Following the strategy of capacitance unequalization, both fundamental consideration and experimental tests have led to prediction of the cell voltage at which oxidation of $\mathrm{Br}^{-}$should occur. When the positrode to negatrode mass ratio increased from $1: 1$ to $3: 1$, the specific energy of the cell increased, but the energy efficiency decreased. Further increasing the mass ratio to $4: 1$ produced a negative effect on the energy storage capacity. The results from this study also show that the cell voltage of the 2-electrode cell can reach $2.00 \mathrm{~V}$ in $\mathrm{KBr}$, but only $1.50 \mathrm{~V}$ in $\mathrm{KI}$.

\section{Acknowledgment}

This work received funding from the International Doctoral Innovation Centre, Ningbo Education Bureau, Ningbo Science and Technology Bureau, and the University of Nottingham, and Ningbo Municipal Government (3315 Plan, 201501CX-C01006 and 2014A35001-1).

\section{ORCID}

Linpo Yu (D) https://orcid.org/0000-0002-9103-9044

Lan Xia (D) https://orcid.org/0000-0002-6347-636X

Chuang Peng (1D https://orcid.org/0000-0001-7943-9873

George Z. Chen (1) https://orcid.org/0000-0002-5589-5767 


\section{References}

1. L. Guan, L. Yu, and G. Z. Chen, Electrochim. Acta, 206, 464 (2016)

2. G. Z. Chen, Prog. Nat. Sci., 23, 245 (2013).

3. J. Li, J. O'Shea, X. Hou, and G. Z. Chen, Chem. Commun., 53, 10414 (2017).

4. M. Rajkumar, C.-T. Hsu, T.-H. Wu, M.-G. Chen, and C.-C. Hu, Prog. Nat. Sci. Mater. Int., 25, 527 (2015).

5. S. Roldan, M. Granda, R. Menendez, R. Santamaria, and C. Blanco, J. Phys. Chem., 115, 17606 (2011).

6. D. Gastol, J. Walkowiak, K. Fic, and E. Frackowiak, J. Power Sources, 326, 587 (2016).

7. Q. Li, K. Li, C. Sun, and Y. Li, J. Electroanal. Chem., 611, 43 (2007).

8. J. Lee, S. Choudhury, D. Weingarth, D. Kim, and V. Presser, ACS Appl. Mater. Inter. 8, $23676(2016)$

9. T.-T. Liu, Y.-H. Zhu, E.-H. Liu, Z.-Y. Luo, T.-T. Hu, Z.-P. Li, and R. Ding, T. Nonferr Metal Soc., 25, 2661 (2015).

10. J. Lee, B. Krüner, A. Tolosa, S. Sathyamoorthi, D. Kim, S. Choudhury, K.-H. Seo, and V. Presser, Energy Environ. Sci., 9, 3392 (2016).

11. T. Shimooka, S. Yamazaki, T. Sugimoto, T. Jyozuka, H. Teraishi, Y. Nagao, H. Oda, Y. Matsuda, and M. Ishikawa, Electrochemistry, 75, 273 (2007).

12. G. Lota, K. Fic, and E. Frackowiak, ElectroChem. Commun., 13, 38 (2011).

13. J. Lee, P. Srimuk, S. Fleischmann, A. Ridder, M. Zeiger, and V. Presser, J. Mater Chem. A, 5, 12520 (2017).

14. Q. Li, M. Haque, V. Kuzmenko, N. Ramani, P. Lundgren, A. D. Smith, and P. Enoksson, J. Power Sources, 348, 219 (2017).

15. B. Gorska, P. Bujewska, and K. Fic, Phys. Chem. Chem. Phys., 19, 7923 (2017).
16. S.-E. Chun, B. Evanko, X. Wang, D. Vonlanthen, X. Ji, G. D. Stucky, and S. W. Boettcher, Nat. Commun., 6, 7818 (2015).

17. B. Evanko, S. J. Yoo, S.-E. Chun, X. Wang, X. Ji, S. W. Boettcher, and G. D. Stucky, J. Am. Chem. Soc., 138, 9373 (2016).

18. S. Sathyamoorthi, M. Kanagaraj, M. Kathiresan, V. Suryanarayanan, and D. Velayutham, J. Mater. Chem. A, 4, 4562 (2016).

19. B. Akinwolemiwa, C. Peng, and G. Z. Chen, J. Electrochem. Soc., 162, A5054 (2015)

20. P. Díaz, Z. González, R. Santamaría, M. Granda, R. Menéndez, and C. Blanco, Electrochim. Acta, 168, 277 (2015).

21. L. Chen, H. Bai, Z. Huang, and L. Li, Energy Environ. Sci., 7, 1750 (2014).

22. K. Fic, M. Meller, J. Menzel, and E. Frackowiak, Electrochim. Acta, 206, 496 (2016).

23. K. Fic, M. Meller, and E. Frackowiak, J. Electrochem. Soc., 162, A5140 (2015).

24. E. Frackowiak, K. Fic, M. Meller, and G. Lota, ChemSusChem, 5, 1181 (2012).

25. C. Peng, S. Zhang, X. Zhou, and G. Z. Chen, Energy Environ. Sci., 3, 1499 (2010)

26. G. Z. Chen, Int. Mater. Rev., 62, 173 (2017).

27. O. Chailapakul, M. Amatatongchai, P. Wilairat, K. Grudpan, and D. Nacapricha, Talanta, 64, 1253 (2004).

28. M. Meller, J. Menzel, K. Fic, D. Gastol, and E. Frackowiak, Solid State Ionics, 265, $61(2014)$.

29. E. Frackowiak, M. Meller, J. Menzel, D. Gastol, and K. Fic, Faraday Discuss., 172, 179 (2014).

30. Z. Dai, C. Peng, J. H. Chae, K. C. Ng, and G. Z. Chen, Sci. Rep., 5, 9854 (2015),

31. P. Przygocki, Q. Abbas, P. Babuchowska, and F. Beguin, Carbon, 125, 391 (2017)

32. X. Tang, Y. H. Lui, B. Chen, and S. Hu, J. Power Sources, 352, 118 (2017).

33. B. Evanko, S. W. Boettcher, S. J. Yoo, and G. D. Stucky, ACS Energy Lett., 2, 2581 (2017). 